\title{
Results of the REIMEP-17 interlaboratory comparison for the measurement of the $U$ and Pu amount content and isotope amount ratios in the synthetic dissolved spent nuclear fuel solution
}

\author{
Rožle Jakopič ${ }^{1} \cdot$ Yetunde Aregbe $^{1} \cdot$ Renáta Buják $^{1} \cdot$ Stephan Richter $^{1} \cdot$ \\ Razvan Buda ${ }^{2} \cdot$ Evelyn Zuleger $^{2}$
}

Received: 6 March 2015/ Accepted: 15 June 2015/Published online: 8 July 2015

(c) The Author(s) 2015. This article is published with open access at Springerlink.com

\begin{abstract}
Reliable measurements are needed for the verification measures of States' declarations of their nuclear activities in line with international agreements and the EURATOM Treaty. Laboratories carrying out measurements of nuclear material need to follow stringent quality control concepts and are required to demonstrate their measurement capabilities on a regular and timely basis to legal and safeguards authorities. This includes participation in interlaboratory comparisons (ILCs). In the frame of the Regular European Interlaboratory Measurement Evaluation Programme (REIMEP), a new ILC (REIMEP-17) was jointly organized by the EC-Joint Research Centre-Institute for Reference Materials and Measurements (JRC-IRMM) and EC-Joint Research Centre-Institute for Transuranium Elements (JRC-ITU) for EURATOM and IAEA safeguards laboratories, nuclear plant operators and nuclear material laboratories. The focus in REIMEP-17 was on measurements of the uranium and plutonium amount contents and isotope amount ratios in synthetic dissolved spent nuclear fuel solutions. Participants received two test samples, REIMEP-17A and REIMEP-17B, with different uranium and plutonium amount contents. Laboratories were requested to report the results with associated uncertainties applying their standard measurement procedures and had the possibility to
\end{abstract}

Rožle Jakopič

rozle.jakopic@ec.europa.eu

1 European Commission - Joint Research Centre, Institute for Reference Materials and Measurements (EC-JRC-IRMM), Retieseweg 111, 2440 Geel, Belgium

2 European Commission - Joint Research Centre, Institute for Transuranium Elements (EC-JRC-ITU), Hermann von Helmholtz Platz 1, 76344 Eggenstein-Leopoldshafen, Germany benchmark those results against the independent assigned (reference) values and the ones listed in the International Target Values for Measurement Uncertainties in Safeguarding Nuclear Materials (ITV2010). It can be concluded that the participants in REIMEP-17 performed well for the measurements of uranium and plutonium amount content in compliance with the respective ITV2010 values. In particular, the measurement performance for the isotope amount ratios was very satisfactory for both REIMEP-17 test samples. This confirms the measurement capabilities of laboratories in the field of nuclear material analysis and demonstrates that the stringent ITV2010 values are achievable targets under state-of-practice conditions. On the other hand, the spread of results for the minor uranium isotope amount ratios was larger. Moreover, for some of the measurands, differences in the measurement uncertainty estimations provided by laboratories were observed even when using the same instrumental technique. A summary of the participant results is presented and discussed in this paper.

Keywords REIMEP-17 - Quality control ·

Nuclear measurements · Interlaboratory comparison .

ITV2010

\section{Introduction}

The aim of nuclear safeguards is the verification of the nondiversion of fissile material from its intended and declared use in line with the Treaty on the Non-Proliferation of Nuclear Weapons (NPT) [1] and the EURATOM Treaty [2]. To achieve this goal, a reliable nuclear material accountancy system has to be established by the plant operator and a reliable verification system by the international or regional 
safeguards authority. Safeguarding nuclear materials involves a quantitative verification of fissile materials by independent measurements. The effectiveness of these verifications depends to a great extent upon the comparison of the measurements achieved by both the facility operator and the safeguards inspectorate. Measurement results accompanied with measurement uncertainty estimations and a traceability statement are best suited for making safeguards evaluations [3]. Measurements of amount content and isotope ratios of uranium and plutonium in samples taken from proliferation-sensitive stages of the nuclear fuel cycle such as enrichment and reprocessing are of great importance [4]. Laboratories carrying out such measurements need to comply with rigorous quality goals and demonstrate their measurement capabilities. One possibility for a laboratory to demonstrate technical competence in line with ISO/IEC 17025:2005 is the successful participation in an interlaboratory comparison (ILC) [5].

The EC-Joint Research Centre-Institute for Reference Materials and Measurements (JRC-IRMM) is an accredited provider of interlaboratory comparisons according to ISO/ IEC 17043:2010 [6]. The Regular European Interlaboratory Measurement Evaluation Programme (REIMEP) was established at the JRC-IRMM in 1982 for carrying out external control of the quality of the measurements of nuclear materials that match samples routinely analysed in the nuclear fuel cycle. Previous REIMEP campaigns included samples such as uranium oxide, uranium in nitric acid, uranium in the form of $\mathrm{UF}_{6}$, plutonium oxide [7]. The focus in REIMEP-17 was on the plutonium and uranium amount content, and isotope amount ratios in synthetic dissolved spent nuclear fuel solutions. It was jointly organized by JRCIRMM and EC-Joint Research Centre-Institute for Transuranium Elements (JRC-ITU) for the EURATOM safeguards laboratories, the IAEA Network of Analytical Laboratories for nuclear material analysis (NWAL), laboratories from industry and experts in the field. Two test samples with different concentrations of plutonium and uranium were prepared to suit laboratories with different objectives. One of the test samples, REIMEP-17A had the uranium and plutonium concentration typical for an undiluted spent nuclear fuel solution, and the other test sample, REIMEP-17B was a diluted fraction of it. A dilution was used to prepare the REIMEP-17B sample purely for practical reasons, resulting in the same isotopic composition for both test samples. The measurands in REIMEP-17 were plutonium and uranium amount contents and $n\left({ }^{238} \mathrm{Pu}\right) / n\left({ }^{239} \mathrm{Pu}\right)$, $n\left({ }^{240} \mathrm{Pu}\right) / n\left({ }^{239} \mathrm{Pu}\right), n\left({ }^{241} \mathrm{Pu}\right) / n\left({ }^{239} \mathrm{Pu}\right), n\left({ }^{242} \mathrm{Pu}\right) / n\left({ }^{239} \mathrm{Pu}\right)$ and $n\left({ }^{234} \mathrm{U}\right) / n\left({ }^{238} \mathrm{U}\right), n\left({ }^{235} \mathrm{U}\right) / n\left({ }^{238} \mathrm{U}\right), n\left({ }^{236} \mathrm{U}\right) / n\left({ }^{238} \mathrm{U}\right)$ amount ratios $\left(\mathrm{mol} \mathrm{mol}^{-1}\right)$. The participants were requested to apply their standard analytical procedures and report the measurement results with associated measurement uncertainties. The results were evaluated against the independent assigned
Table 1 Laboratories participating in REIMEP-17 interlaboratory comparison

\begin{tabular}{|c|c|c|}
\hline Laboratory & Country & Name \\
\hline $\begin{array}{l}\text { SCK-CEN Belgian Nuclear } \\
\text { Research Centre }\end{array}$ & Belgium & SCK-CEN \\
\hline $\begin{array}{l}\text { Nuclear Material Laboratory, Office } \\
\text { of Safeguards Analytical } \\
\text { Services, IAEA }\end{array}$ & Austria & IAEA-NML \\
\hline $\begin{array}{l}\text { On-Site Laboratory, Office of } \\
\text { Safeguards Analytical Services, } \\
\text { IAEA }\end{array}$ & Japan & IAEA-OSL \\
\hline $\begin{array}{l}\text { Nuclear Research and Consultancy } \\
\text { Group (NRG), Petten }\end{array}$ & The Netherlands & NRG-Petten \\
\hline $\begin{array}{l}\text { Sellafield Limited, Analytical } \\
\text { Services }\end{array}$ & United Kingdom & Sellafield Ltd \\
\hline $\begin{array}{l}\text { EURATOM On-site Laboratory, } \\
\text { Sellafield }\end{array}$ & United Kingdom & ITU-OSL \\
\hline $\begin{array}{l}\text { EURATOM Laboratoire sur Site, } \\
\text { La Hague }\end{array}$ & France & ITU-LSS \\
\hline $\begin{array}{l}\text { French Alternative Energies and } \\
\text { Atomic Energy Commission } \\
\text { (CEA), LAMM, Marcoule }\end{array}$ & France & CEA-LAMM \\
\hline $\begin{array}{l}\text { French Alternative Energies and } \\
\text { Atomic Energy Commission } \\
\text { (CEA), LANIE, Saclay }\end{array}$ & France & CEA-LANIE \\
\hline
\end{tabular}

values and international quality goals by means of $z$ scores and zeta scores in compliance with ISO 13528:2005 [8] and with ISO 17043:2010 [6]. The quality goals for nuclear material analysis are defined in the document International Target Values for Measurement Uncertainties in Safeguarding Nuclear Materials (ITV2010) [9]. They represent the estimates of the "state of the practice" which should be achievable under routine measurement conditions in a typical industrial laboratory or during actual safeguards inspections [9]. The list of participating laboratories in REIMEP-17 is presented in Table 1.

\section{Test samples}

Participants received two test samples, REIMEP-17A and REIMEP-17B, with different uranium and plutonium amount contents. The REIMEP-17A sample solution was prepared by dissolution of a sample of an unirradiated mixed oxide fuel in nitric acid and the addition of natural uranium, aiming at the mass fraction of uranium and plutonium of about $200 \mathrm{mg} \mathrm{g}^{-1}$ and $2 \mathrm{mg} \mathrm{g}^{-1}$, respectively. Other impurities (e.g. fission products) were not added for transport purposes. The REIMEP-17B sample solution was prepared by a 400-fold dilution of REIMEP-17A resulting in a mass fraction of uranium and plutonium of about $500 \mathrm{mg} \mathrm{g}^{-1}$ and $5 \mu \mathrm{g} \mathrm{g}^{-1}$, respectively. The isotope ratios 
of uranium and plutonium were in the range of depleted uranium $\left[0.67 \mathrm{~g} /(100 \mathrm{~g}){ }^{235} \mathrm{U}\right]$ and high burn-up plutonium. The solutions were dispensed into glass ampoules and laser-sealed. Each ampoule contained about $6 \mathrm{~mL}$ of solution. The preparation of the test samples and shipment to the participants were carried out by JRC-ITU.

The assigned (reference) values for the plutonium and uranium amount content and isotope amount ratios were established at JRC-IRMM in combination with homogeneity and stability assessment by isotope dilution mass spectrometry (IDMS) and thermal ionization mass spectrometry (TIMS) on randomly selected ampoules. Five ampoules of each fraction (REIMEP-17A and REIMEP$17 \mathrm{~B})$ were analysed in three replicate measurements. Isotope ratio measurements were performed by total evaporation (TE) on a Triton TIMS (Thermo Fisher Scientific, Bremen) [10-12] after chemical purification by anion exchange. Details on the preparation and characterization of the test material can be found in the REIMEP-17 report [13]. The assigned values for REIMEP-17A and REIMEP-17B are presented in Table 2.

\section{Evaluation of laboratory performance in REIMEP-17}

All REIMEP-17 participant results were evaluated against the assigned values by means of $z$ scores and zeta scores in compliance with ISO 13528:2005 [8]. The ITV2010 target values were used as a standard deviation $(\hat{\sigma})$ for proficiency assessment to score the participant results.

$z=\frac{x_{\mathrm{lab}}-X_{\mathrm{ref}}}{\hat{\sigma}}$ $z e t a=\frac{x_{\mathrm{lab}}-X_{\mathrm{ref}}}{\sqrt{u_{\mathrm{lab}}^{2}+u_{\mathrm{ref}}^{2}}}$

where

$x_{\mathrm{lab}}$ is the measurement result reported by a participant,

$X_{\text {ref }}$ is the assigned value,

$u_{\mathrm{ref}}$ is the standard measurement uncertainty of the assigned value,

$u_{\text {lab }}$ is the standard measurement uncertainty reported by a participant, and

$\hat{\sigma} \quad$ is the standard deviation for proficiency assessment

$z$ scores can be interpreted as follows:

satisfactory performance for $|z| \leq 2$,

questionable performance for $2<|z| \leq 3$

unsatisfactory performance for $|z|>3$. An identical ranking applies to zeta scores

Measurement performance evaluation in REIMEP-17 was done according to the purpose of the measurement and the possible use of the result. The ITV2010 values are expressed as relative combined standard uncertainties; therefore, in addition to scoring as recommended in ISO 13528:2005, a performance assessment criterion for a minimum and maximum acceptable measurement uncertainty was applied to complete satisfactory performance that take reported measurement uncertainties into account.

The range of acceptable standard measurement uncertainty reported by a participant with a satisfactory performance expressed by zeta score has been evaluated as such:

For all $\mid$ zetal $\leq 2$, it is evaluated whether $u_{\min }<u_{\text {lab }} \leq$ $u_{\max }$, where $u_{\min }=0, u_{\text {lab }}=u_{\text {lab;rel }}$ and the respective ITV2010 values serve as $u_{\max }$ [9].

Table 2 REIMEP-17: plutonium and uranium amount content and isotope amount ratios in synthetic dissolved spent nuclear fuel solution assigned values

\begin{tabular}{|c|c|c|c|c|}
\hline Test sample & Measurand & Unit & Assigned value ${ }^{\mathrm{a}}$ & Uncertainty $^{\mathrm{b}}$ \\
\hline \multirow[t]{2}{*}{ REIMEP-17A } & $\mathrm{Pu}$ amount content & $\mu \mathrm{mol} \mathrm{g}{ }^{-1}$ & 9.1561 & 0.0050 \\
\hline & $\mathrm{U}$ amount content & $\mu \mathrm{mol} \mathrm{g}{ }^{-1}$ & 843.42 & 0.50 \\
\hline \multirow[t]{2}{*}{ REIMEP-17B } & $\mathrm{Pu}$ amount content & $\mu \mathrm{mol} \mathrm{g}{ }^{-1}$ & 0.022976 & 0.000013 \\
\hline & $\mathrm{U}$ amount content & $\mu \mathrm{mol} \mathrm{g}^{-1}$ & 2.1167 & 0.0020 \\
\hline \multirow[t]{7}{*}{ REIMEP-17A, 17B } & $n\left({ }^{234} \mathrm{U}\right) / n\left({ }^{238} \mathrm{U}\right)$ & $\mathrm{mol} \mathrm{mol}^{-1}$ & 0.0000657 & 0.0000015 \\
\hline & $n\left({ }^{235} \mathrm{U}\right) / n\left({ }^{238} \mathrm{U}\right)$ & $\mathrm{mol} \mathrm{mol}^{-1}$ & 0.0068092 & 0.0000057 \\
\hline & $n\left({ }^{236} \mathrm{U}\right) / n\left({ }^{238} \mathrm{U}\right)$ & $\mathrm{mol} \mathrm{mol}^{-1}$ & 0.0000029 & 0.0000015 \\
\hline & $n\left({ }^{238} \mathrm{Pu}\right) / n\left({ }^{239} \mathrm{Pu}\right)$ & $\mathrm{mol} \mathrm{mol}^{-1}$ & 0.042596 & 0.000042 \\
\hline & $n\left({ }^{240} \mathrm{Pu}\right) / n\left({ }^{239} \mathrm{Pu}\right)$ & $\mathrm{mol} \mathrm{mol}^{-1}$ & 0.478692 & 0.000055 \\
\hline & $n\left({ }^{241} \mathrm{Pu}\right) / n\left({ }^{239} \mathrm{Pu}\right)$ & $\mathrm{mol} \mathrm{mol}^{-1}$ & 0.12573 & 0.00023 \\
\hline & $n\left({ }^{242} \mathrm{Pu}\right) / n\left({ }^{239} \mathrm{Pu}\right)$ & $\mathrm{mol} \mathrm{mol}^{-1}$ & 0.137468 & 0.000038 \\
\hline
\end{tabular}

${ }^{a}$ The reference date for the assigned (reference) values is 1 March 2013

${ }^{\mathrm{b}}$ Expanded uncertainty with a coverage factor $k=2$ at a confidence level $95 \%$ estimated in accordance with Guide to the Expression of Uncertainty in Measurement (ISO GUM [14]) 
Table 3 The ITV2010 values expressed as combined relative standard uncertainties

\begin{tabular}{|c|c|c|c|}
\hline Method & Measurand & ITV2010 criterion $(\%)$ & Material description \\
\hline \multirow[t]{2}{*}{ IDMS } & $\mathrm{U}$ amount content & $0.18^{\mathrm{a}}$ & All materials \\
\hline & $\mathrm{Pu}$ amount content & & \\
\hline \multirow[t]{2}{*}{ IDMS } & $\mathrm{U}$ amount content & $0.28^{\mathrm{b}}$ & All materials \\
\hline & $\mathrm{Pu}$ amount content & & \\
\hline TIMS, ICP-MS & $n\left({ }^{234} \mathrm{U}\right) / n\left({ }^{238} \mathrm{U}\right)$ & n.a. & $0.3 \%<m\left({ }^{235} \mathrm{U}\right) / m(\mathrm{U})<1 \%$ \\
\hline TIMS, ICP-MS & $n\left({ }^{235} \mathrm{U}\right) / n\left({ }^{238} \mathrm{U}\right)$ & 0.28 & $0.3 \%<m\left({ }^{235} \mathrm{U}\right) / m(\mathrm{U})<1 \%$ \\
\hline TIMS, ICP-MS & $n\left({ }^{236} \mathrm{U}\right) / n\left({ }^{238} \mathrm{U}\right)$ & n.a. & $0.3 \%<m\left({ }^{235} \mathrm{U}\right) / m(\mathrm{U})<1 \%$ \\
\hline TIMS, ICP-MS, alpha spectrometry & $n\left({ }^{238} \mathrm{Pu}\right) / n\left({ }^{239} \mathrm{Pu}\right)$ & 1.80 & High burn-up Pu \\
\hline TIMS, ICP-MS & $n\left({ }^{240} \mathrm{Pu}\right) / n\left({ }^{239} \mathrm{Pu}\right)$ & 0.11 & High burn-up Pu \\
\hline TIMS, ICP-MS & $n\left({ }^{241} \mathrm{Pu}\right) / n\left({ }^{239} \mathrm{Pu}\right)$ & 0.28 & High burn-up Pu \\
\hline TIMS, ICP-MS & $n\left({ }^{242} \mathrm{Pu}\right) / n\left({ }^{239} \mathrm{Pu}\right)$ & 0.36 & High burn-up Pu \\
\hline
\end{tabular}

$m\left({ }^{235} \mathrm{U}\right) / m(\mathrm{U})$ mass fraction $\left(\mathrm{g} \mathrm{g}^{-1}\right)$

n.a. not applicable

${ }^{a}$ Large-size spikes (glove box conditions)

b Small-size spikes (glove box conditions), large-size spikes (hot cell conditions)

As mentioned earlier, the respective ITV2010 values were used as the standard deviation for proficiency assessment in REIMEP-17. These depend on the instrumental/analytical technique and the type of spike and conditions applied in the analysis [9]. Table 3 summarizes the ITV2010 values applied in the evaluation of REIMEP17 results. According to the IUPAC International Harmonised Protocol, participants can apply their own scoring settings and recalculate the scores if the purpose of their measurements is different [15].

\section{Participant results}

The laboratory results were coded A through $\mathrm{J}$. There is no correlation between the laboratory code and the order of the laboratories presented in Table 1. One laboratory received two sets of test samples and submitted results for both sets. Therefore, 10 codes were assigned for a total of 9 laboratories. As shown in Figs. 1 and 2, the individual results are presented in graphs as a relative deviation from the assigned reference value. The results from the stability assessment (with expanded uncertainty, $k=2$ ) are shown together with the participants' results. The stability measurements were carried out by JRC-IRMM about a year after the production of the test samples to demonstrate the stability of the sample solution during the interlaboratory comparison. One ampoule of each fraction, REIMEP-17A and REIMEP-17B, was analysed in three replicate measurements. All stability measurements confirmed the REIMEP-17 assigned values.

Isotope dilution in combination with thermal ionization mass spectrometry (ID-TIMS) or inductively coupled- plasma mass spectrometry (ID-ICP-MS) was utilized by the participants for the determination of the amount content. One laboratory used X-ray fluorescence (XRF) for determination of the amount content in the REIMEP-17B sample. All participants performed a chemical separation prior to the isotope ratio measurements. The results for the uranium amount content in REIMEP-17A are shown in Fig. 1.

Depending on the analytical approach chosen by laboratories, two different ITV2010 criteria can be applied for the calculation of $z$ scores and zeta scores for the amount content (see Table 3). However, in this paper, the results evaluated with the ITV2010 criterion $0.28 \%$ are presented because the majority of laboratories analysed the REIMEP17 samples under conditions appropriate to this value. A detailed evaluation of the participants' results can be found in the REIMEP-17 report [13]. The $z$ and zeta scores for the uranium amount content in REIMEP-17A are shown in Fig. 2.

Good performance was observed among the participants for the determination of the $U$ amount content in REIMEP17A. Laboratories A, B, C, F, I and J achieved satisfactory performance in terms of $z$ and zeta scores as shown in Fig. 2. Laboratory D reported a result exceeding the ITV2010 value and achieved unsatisfactory performance. Figures 1 and 2 show that the laboratories $G$ and $H$ underestimated their measurement uncertainty. This led to unsatisfactory performance in terms of zeta scores for both laboratories. A possible explanation for this could be in an incomplete uncertainty estimation, where the laboratory reported an estimate for the measurement precision under a set of repeatability conditions instead of a more comprehensive measurement uncertainty estimation [16]. 
Fig. 1 Participant results of the $\mathrm{U}$ amount content, $v(\mathrm{U})$, in REIMEP-17A with

measurement uncertainties (error bars) as reported by the participants (laboratories A and I reported $k=1$; all other results and the stability value were reported with expanded uncertainties, $k=2$ ). The grey band represents the assigned value with expanded uncertainty $(k=2)$. The dashed line represents the respective ITV2010 value. The dashed squares indicate the laboratories applying ISO GUM [14] methodology for the evaluation of the measurement uncertainty
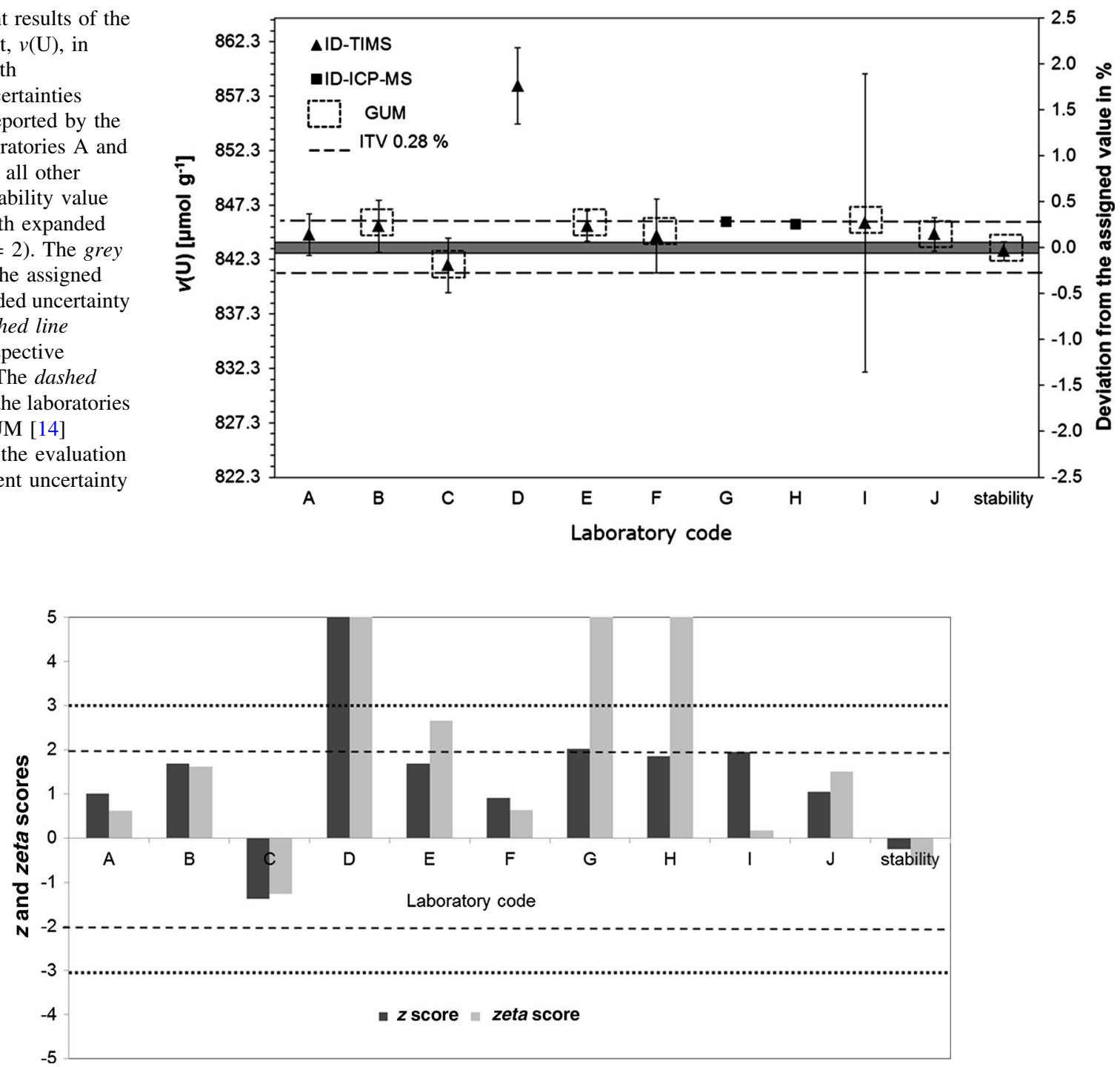

Fig. 2 The $z$ and $z$ eta scores for the U amount content in REIMEP-17A. The dashed and dotted lines indicate $z$ or $z$ eta $=2$ and $z$ or $z$ eta $=3$, respectively

Uncertainties reported by the participants were also evaluated to see whether they were within the acceptable uncertainty range for the respective measurands. The maximum acceptable measurement uncertainty for the uranium amount content expressed as a relative standard deviation was $0.28 \%$ (ITV2010). All laboratories with satisfactory performance (zeta scores) reported their relative measurement uncertainty below this threshold except laboratory I, which drastically overestimated its measurement uncertainty.

Three laboratories did not submit results for REIMEP17B. Among the remaining laboratories, good performance for the uranium amount content was observed. Only one laboratory achieved unsatisfactory performance $(z$ and zeta scores). One laboratory reported the "less than" value $\left[v(\mathrm{U})<2.5 \mu \mathrm{mol} \mathrm{g}^{-1}\right]$; however, no scores could be calculated for this laboratory. Similar to the measurements on the REIMEP-17A samples, in some cases, the reported uncertainties appeared to be somewhat overestimated.

The overall performance for the plutonium amount content in REIMEP-17 was good; however, fewer laboratories achieved satisfactory performance compared to the the measurements of uranium. For REIMEP-17A, four laboratories achieved satisfactory performance in terms of $z$ and zeta scores, and among them, three reported their measurement uncertainties within the maximum acceptable range. For REIMEP-17B, only two laboratories achieved satisfactory performance. The results for the plutonium amount content in REIMEP-17B are shown in Fig. 3.

The result by laboratory I included a significant bias: the reported value was by two orders of magnitude higher than the assigned value. This could be due to a contamination 
Fig. 3 Participant results of the $\mathrm{Pu}$ amount content $v(\mathrm{Pu})$ in REIMEP-17B with measurement uncertainties (error bars) as reported by the participants (laboratory I reported $k=1$; all other results and the stability value were reported with expanded uncertainty, $k=2$ ). The grey band represents the assigned value with the expanded uncertainty $(k=2)$. The dashed line represents the respective ITV2010 value. The dashed squares indicate the laboratories applying ISO GUM [14] methodology for the evaluation of the measurement uncertainty

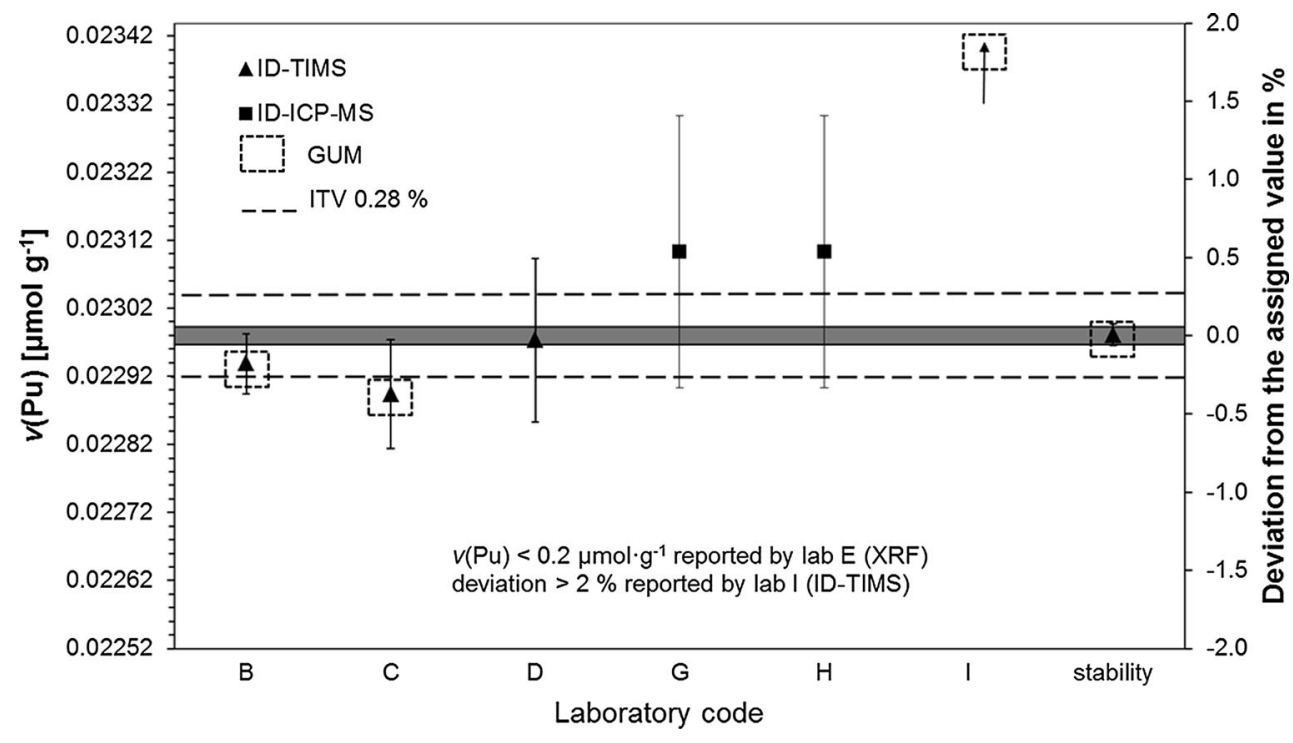

problem or a calculation error. Laboratories $\mathrm{G}$ and $\mathrm{H}$ also reported the results outside the ITV2010 criterion; therefore, in all three cases, unsatisfactory performance in terms of $z$ scores was achieved. Laboratory E reported the "less than" value $\left[v(\mathrm{Pu})<0.2 \mu \mathrm{mol} \mathrm{g}{ }^{-1}\right]$. Laboratories $\mathrm{A}, \mathrm{F}$ and $\mathrm{J}$ did not submit their results because the amounts of uranium and plutonium in REIMEP-17B were too low to be treated as a routine nuclear material sample in their laboratories. Some inconsistency in the estimation of measurement uncertainty was observed for the laboratories $\mathrm{G}$ and $\mathrm{H}$. Reported uncertainties appeared to be overestimated for the REIMEP-17B, but underestimated for the REIMEP-17A test sample for the same measurand.

For the measurement of the amount ratios, participants applied either TIMS or ICP-MS with five laboratories utilizing the total evaporation technique. For the measurement of the $n\left({ }^{238} \mathrm{Pu}\right) / n\left({ }^{239} \mathrm{Pu}\right)$ ratio, five laboratories applied alpha spectrometry. The results for the $n\left({ }^{235} \mathrm{U}\right) /$ $n\left({ }^{238} \mathrm{U}\right)$ ratio in REIMEP-17A are shown in Fig. 4.

Very good performance was observed for the $n\left({ }^{235} \mathrm{U}\right) /$ $n\left({ }^{238} \mathrm{U}\right)$ amount ratio. From Fig. 4 it can be taken that the laboratory $\mathrm{G}$ showed a bias of about $0.8 \%$ and therefore obtained unsatisfactory performance in terms of $z$ score. Laboratory $\mathrm{G}$ also showed a bias in the $n\left({ }^{234} \mathrm{U}\right) / n\left({ }^{238} \mathrm{U}\right)$ amount ratio in the same test sample. Contamination with natural uranium could explain this deviation, or it could also be a result of an incorrect mass fractionation correction due to the use of a non-TE method. The laboratories D and $\mathrm{H}$ overestimated their measurement uncertainties. On the other hand, excellent performance was observed for the laboratories using TIMS in combination with the total evaporation technique.
Fig. 4 Participant results of the amount ratio $n\left({ }^{235} \mathrm{U}\right) / n\left({ }^{238} \mathrm{U}\right)$ in REIMEP-17A with measurement uncertainties (error bars) as reported by the participants (laboratory A reported $k=1$; all other results and the stability value were reported with expanded uncertainty, $k=2$ ). The grey band represents the assigned value with the expanded uncertainty $(k=2)$. The dashed line represents the respective ITV2010 value. The dotted circles indicate the laboratories using the total evaporation technique

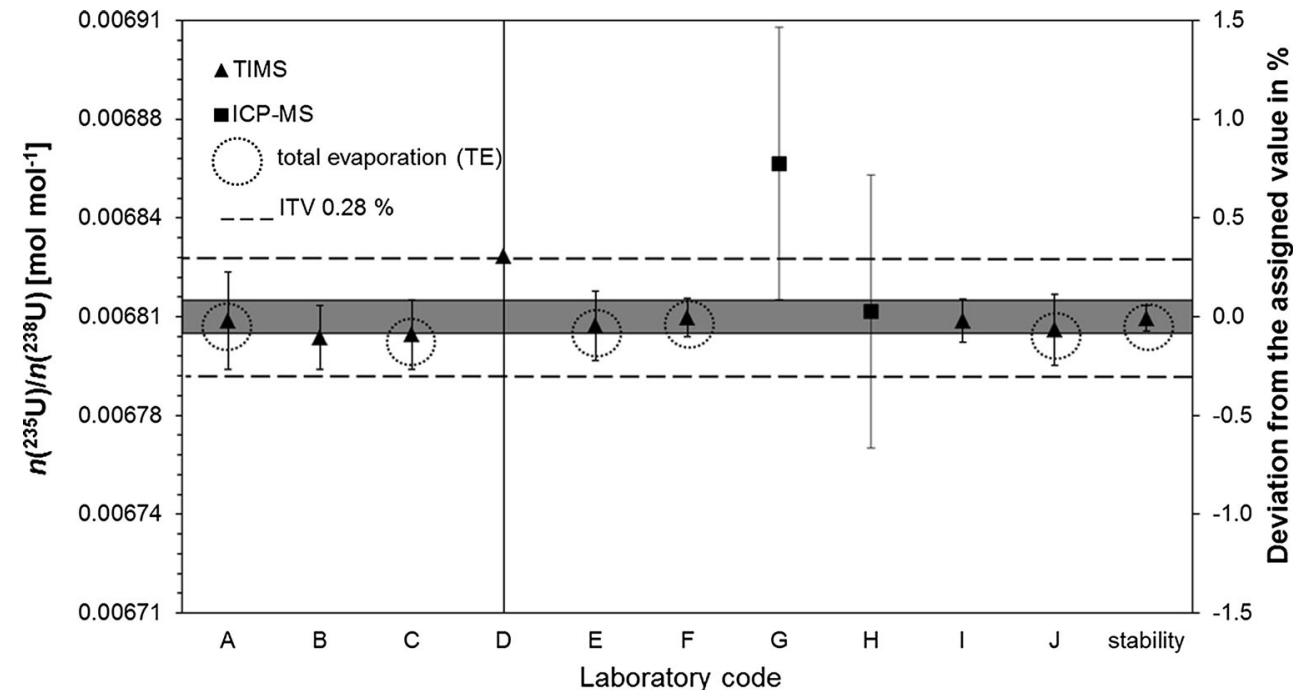


Fig. 5 Participant results of the amount ratio $n\left({ }^{240} \mathrm{Pu}\right) / n\left({ }^{239} \mathrm{Pu}\right)$ in REIMEP-17B with measurement uncertainties (error bars) as reported by the participants (all results and the stability value were reported with expanded uncertainty, $k=2$ ). The grey band represents the assigned value with the expanded uncertainty $(k=2)$. The dashed line represents the respective ITV2010 value. The dotted circles indicate the laboratories using the total evaporation technique

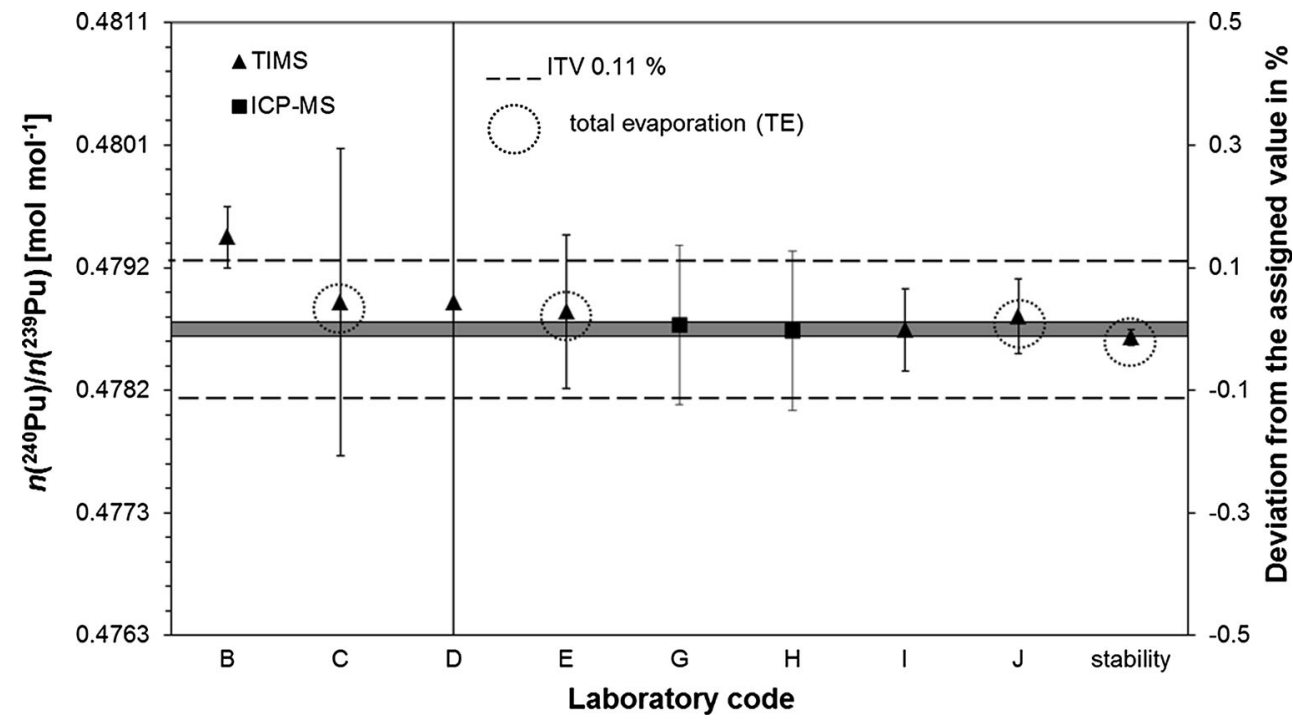

Excellent performance was also observed for the $n\left({ }^{235} \mathrm{U}\right) / n\left({ }^{238} \mathrm{U}\right)$ amount ratio in REIMEP-17B, where all laboratories that reported the results except one achieved satisfactory performance (zeta and $z$ scores). As already observed with REIMEP-17A, the laboratory D overestimated its measurement uncertainty. Two laboratories did not submit their results.

The majority of the participants also reported the results for the minor uranium ratios. As there are no ITV2010 values defined for $n\left({ }^{234} \mathrm{U}\right) / n\left({ }^{238} \mathrm{U}\right)$ and $n\left({ }^{236} \mathrm{U}\right) / n\left({ }^{238} \mathrm{U}\right)$, only zeta scores were provided to the participants. Overall, good performance was observed for the $n\left({ }^{234} \mathrm{U}\right) / n\left({ }^{238} \mathrm{U}\right)$ amount ratio. Satisfactory performance in terms of zeta scores was achieved by $60 \%$ of the participants in REIMEP-17A and $88 \%$ in REIMEP-17B, respectively. On the other hand, very few laboratories obtained satisfactory performance for the amount ratio $n\left({ }^{236} \mathrm{U}\right) / n\left({ }^{238} \mathrm{U}\right)$. Some laboratories either reported only an upper value or did not submit the result for this ratio at all.

Excellent performance was observed for the amount ratio $n\left({ }^{240} \mathrm{Pu}\right) / n\left({ }^{239} \mathrm{Pu}\right)$ in REIMEP-17. As an example, the results for the amount ratio $n\left({ }^{240} \mathrm{Pu}\right) / n\left({ }^{239} \mathrm{Pu}\right)$ in REIMEP17B are shown in Fig. 5.

All the laboratories except laboratory B achieved satisfactory performance. From Fig. 5 it is obvious that laboratories $\mathrm{C}$ and $\mathrm{D}$ overestimated their measurement uncertainty. With REIMEP-17A, all the laboratories achieved satisfactory performance for the $n\left({ }^{240} \mathrm{Pu}\right) / n\left({ }^{239} \mathrm{Pu}\right)$ amount ratio. Moreover, an excellent performance was observed for other plutonium amount ratios in REIMEP-17A and for the $n\left({ }^{242} \mathrm{Pu}\right) / n\left({ }^{239} \mathrm{Pu}\right)$ amount ratio in REIMEP-17B. Regarding the amount ratio $n\left({ }^{238} \mathrm{Pu}\right) / n\left({ }^{239} \mathrm{Pu}\right)$, in some cases the results exceeded the ITV2010 values [13].

In REIMEP campaigns, the participant measurement results are evaluated against independent reference values.
In addition in this paper, we also applied the robust statistics as a comparison. The determination of the robust statistics allows the assigned values to be compared with the mean results reported by the participants (so-called the consensus value). This approach is usually applied when it is suspected that the population of the results includes a few extreme outliers. The robust mean $\left(X_{\mathrm{rob}}\right)$ and the robust standard deviation $\left(s_{\text {rob }}\right)$ of the participants' results are calculated by the Algorithm A specified in standards ISO 5725-5 [17] and ISO 13528:2005 [8]. The compatibility [16] between the robust mean and the assigned values is represented by $\Delta / u_{\mathrm{d}}$, calculated according to the following equations:

$\Delta=X_{\text {rob }}-X_{\text {ref }}$

$u_{\mathrm{d}}=\sqrt{u_{\mathrm{rob}}^{2}+u_{\mathrm{ref}}^{2}}$

where

$X_{\text {rob }}$ is the robust mean of the participants' results,

$X_{\text {ref }}$ is the assigned value,

$u_{\text {ref }}$ is the standard measurement uncertainty of the assigned value, and

$u_{\text {rob }}$ is the standard measurement uncertainty of the robust mean which is calculated according to the following equation:

$u_{\mathrm{rob}}=\frac{1.25 s_{\mathrm{rob}}}{\sqrt{p}}$

where

$s_{\text {rob }}$ is the robust standard deviation of the participants calculated using Algorithm A and

$p \quad$ is the number of reported results 
Table 4 Results of the robust statistics for REIMEP-17A and REIMEP-17B

\begin{tabular}{|c|c|c|c|c|c|c|}
\hline Measurand & Unit & $X_{\text {ref }}$ & $U_{\text {ref }}$ & $X_{\text {rob }}$ & $U_{\text {rob }}$ & $\Delta / u_{\mathrm{d}}$ \\
\hline U amount content, REIMEP-17A & $\mu \mathrm{mol} \mathrm{g}{ }^{-1}$ & 843.42 & 0.25 & 845.21 & 0.33 & 4.33 \\
\hline$n\left({ }^{235} \mathrm{U}\right) / n\left({ }^{238} \mathrm{U}\right)$, REIMEP-17A & $\mathrm{mol} \mathrm{mol}^{-1}$ & 0.0068092 & 0.00000285 & 0.0068084 & 0.0000023 & -0.21 \\
\hline $\mathrm{Pu}$ amount content, REIMEP-17B & $\mu \mathrm{mol} \mathrm{g}{ }^{-1}$ & 0.022976 & 0.0000065 & 0.023040 & 0.00077 & 0.83 \\
\hline$n\left({ }^{240} \mathrm{Pu}\right) / n\left({ }^{239} \mathrm{Pu}\right)$, REIMEP-17B & $\mathrm{mol} \mathrm{mol}^{-1}$ & 0.478692 & 0.0000275 & 0.478815 & 0.000057 & 1.93 \\
\hline
\end{tabular}

The outcome of the robust statistics for the $U$ amount content and the $n\left({ }^{235} \mathrm{U}\right) / n\left({ }^{238} \mathrm{U}\right)$ amount ratio in REIMEP$17 \mathrm{~A}$ and for the $\mathrm{Pu}$ amount content and the $n\left({ }^{240} \mathrm{Pu}\right)$ / $n\left({ }^{239} \mathrm{Pu}\right)$ amount ratio in REIMEP-17B is shown in Table 4.

It can be concluded that the robust means and the assigned values are compatible $\left(\left|\Delta / u_{\mathrm{d}}\right| \leq 2\right)$ for the abovementioned measurands, except for the $U$ amount content in REIMEP-17A. Nevertheless, the assigned value of the $U$ amount content in REIMEP-17A mother solution was verified by IDMS at JRC-ITU $\left(\left|\Delta / u_{\mathrm{d}}\right|=0.006\right)$.

\section{Discussion}

In REIMEP-17, two test samples with different concentration of uranium and plutonium were prepared to accommodate laboratories with different objectives. One test sample was representative of undiluted dissolved spent nuclear fuel solution; the other test sample was a diluted fraction of it. The mission of most of the participating laboratories was to carry out measurement for fissile material control or safeguards. Some laboratories were also involved in research and development or medical application.

It can be concluded that the participants performed well for the measurements of uranium and plutonium amount content in compliance with the respective values of ITV2010, except for the plutonium amount content in the REIMEP-17B sample where the performance was less satisfactory. In particular, the measurement performance for the plutonium isotope amount ratios and the uranium major ratio was very good for both REIMEP-17 samples. Excellent performance was observed among the laboratories using the TE method. Some larger spread of the results was observed for the minor uranium amount ratios.

With respect to measurement uncertainties, all the laboratories reported measurement uncertainties for the REIMEP-17A sample, and $60 \%$ of the laboratories followed the ISO GUM methodology [14]. The measurement uncertainty of these laboratories were comparable and, in most cases, within the maximum acceptable range for the respective measurand. In one case, ITV values were reported as measurement uncertainties. Two laboratories stated that they do not routinely report measurement uncertainties. Some differences in the measurement uncertainty estimations were observed even for the same instrumental technique. The laboratories which utilized the TE method had comparable estimates of measurement uncertainties, whereas the laboratories using a non-TE (e.g. classical method) in many cases either overestimated or underestimated their measurement uncertainties. Laboratories applying alpha spectrometry demonstrated that this technique, within its larger uncertainties compared to TIMS, provides reliable results for the measurement of the $n\left({ }^{238} \mathrm{Pu}\right) / n\left({ }^{239} \mathrm{Pu}\right)$ isotope amount ratio. A tendency was noticed towards reporting uncertainties overestimated for the REIMEP-17B and underestimated for the REIMEP-17A sample for the same measurand. This might be due to the fact that in some cases, measurement precision has been reported instead of a combined measurement uncertainty. At this point, it must be recalled that the main mission of the participating laboratories was to carry out measurements for fissile material control or safeguards, whereas a sample such as REIMEP-17B with a mass fraction of uranium and plutonium of about $500 \mu \mathrm{g} \mathrm{g}^{-1}$ and $5 \mu \mathrm{g} \mathrm{g}^{-1}$, respectively, might not be the type of sample usually analysed in these laboratories. Therefore, the routine analytical procedures of some of the participants in REIMEP-17 were probably not optimized for measuring samples with lower uranium and plutonium concentrations. All laboratories reported the use of certified reference materials for instrument calibration or method validation.

\section{Conclusion}

Nuclear safeguards in the European Union has the rank of European law (Euratom treaty, Chapter VII, Euratom regulation 302/2005). A prerequisite for any analytical method used to draw conclusions in nuclear safeguards is to deliver accurate measurement results. Measurement results for 
nuclear material accountancy and safeguards verification purposes have to be fit for intended use and within the required measurement uncertainties of the ITV2010 [9]. In recent ESARDA workshops and IAEA technical meetings, recommendations were given on quality control to ensure confidence in the measurement results, with emphasis on traceability of measurement results and reliable measurement uncertainty estimations under routine analytical conditions [3, 4]. The ITV2010 provides the most suitable fit-for-purpose quality goals to assess the measurement capability of EURATOM safeguards laboratories, the IAEA Network of Analytical Laboratories (NWALs) for nuclear material analysis and operators' measurement systems. REIMEP-17 interlaboratory comparison demonstrated the measurement capabilities of the laboratories in the field of nuclear material analysis and at the same time served as a confirmation that the ITV2010 values are achievable and fit-for-purpose target values under state-ofpractice conditions. Because of possible interferences from fission products in the chemical purification stages and also from transuranium elements in the mass-spectrometry measurements, it is to be expected that the measurement performance of laboratories on the real dissolved spent nuclear fuel sample solution would be less satisfactory. Due to limitations in the transport of radioactive samples, no such real samples could be prepared for this interlaboratory comparison. The provision of quality control tools for conformity assessment, such as REIMEP-17, thus, directly contributes to the effectiveness of the safeguards system.

Acknowledgments The authors would like to thank Frances Kehoe from JRC-IRMM for her help with chemical separation and TIMS measurements for the characterization, homogeneity and stability assessments of the test samples. The authors would also like to thank the colleagues from JRC-ITU Ramon Carlos-Marquez, Lorenza Emblico, Anna Sanchez-Hernandez and Martin Vargas-Zuniga for the preparation, the sealing and the packing of the test samples for transport, and Joan Horta, Eckhard Dahms and Sylvain Millet for the initial characterization and stability measurements.

\section{Compliance with Ethical Standards}

Conflict of interest The authors declare that they have no conflict of interest.

Open Access This article is distributed under the terms of the Creative Commons Attribution 4.0 International License (http://creativecommons.org/licenses/by/4.0/), which permits unrestricted use, distribution, and reproduction in any medium, provided you give appropriate credit to the original author(s) and the source, provide a link to the Creative Commons license, and indicate if changes were made.

\section{References}

1. The structure and content of agreements between the agency and states required in connection with the Treaty on the non-proliferation of nuclear weapons, INFCIRC/153 (corrected), Vienna, June 1972. https://www.iaea.org/publications/documents/infcircs/ structure-and-content-agreements-between-agency-and-statesrequired

2. Consolidated version of the treaty establishing the European Atomic Energy Community, Official Journal of the European Union, 2012/C 327/01. http://eur-lex.europa.eu/legal-content/EN/ TXT/?uri=CELEX:12012A/TXT

3. Aregbe Y, Jakopič R, Richter S, Venchiarutti C (2014) Conformity assessment in nuclear material and environmental sample analysis. In: Proceeding paper IAEA Safeguards symposium, ID 160; http:// www.iaea.org/safeguards/symposium/2014/home/index.html

4. Tushingham J (2013) Focused working group activities on the subject of measurement uncertainties and reference material needs. ESARDA Bulletin, No. 50, pp 126-128

5. ISO/IEC 17025:2005: General requirements for the competence of testing and calibration laboratories. International Organization for Standardization, Geneva

6. ISO/IEC 17043: 2010: Conformity assessment—general requirements for proficiency testing. International Organization for Standardization, Geneva

7. https://ec.europa.eu/jrc/en/interlaboratory-comparisons/REIMEP

8. ISO 13528:2005: Statistical methods for use in proficiency testing by inter-laboratory comparison. International Organization for Standardization, Geneva

9. International target values 2010 for measurement uncertainties in safeguarding nuclear materials, IAEA-STR-368, Vienna, November 2010. https://www.inmm.org/AM/Template.cfm? Section=ITVs\&Template $=/ \mathrm{CM} /$ ContentDisplay. $\mathrm{cfm} \&$ ContentID $=$ 2256

10. Richter S, Goldberg SA (2003) Improved techniques for high accuracy isotope ratio measurement of nuclear materials using thermal ionization mass spectrometry. Int J Mass Spectrom 229:181-197

11. Bürger S, Balsley SD, Baumann SD, Berger J, Boulyga SF, Cunningham JA, Kappel S, Kopft A, Poths J (2012) Uranium and plutonium analysis of nuclear material samples by multi-collector thermal ionization mass spectrometry: quality control, measurement uncertainty, and metrological traceability. Int $\mathrm{J}$ Mass Spectrom 311:40-50

12. Callis EL, Abernathey RM (1991) High precision isotopic analyses of uranium and plutonium by total sample volatilization and signal integration. Int J Mass Spectrom Ion Process 103:322-327

13. Jakopič R, Bujak R, Aregbe Y, Richter S, Buda R, Zuleger E (2014): REIMEP-17: plutonium and uranium amount content, and isotope amount ratios in synthetic input solution. Report EUR $26667 \mathrm{EN}$

14. Evaluation of measurement data-guide to the expression of uncertainty in measurement (ISO GUM:2008), JCGM-100: 2008

15. The IUPAC International Harmonised Protocol, Thompson M, Ellison MLR, Wood R (2006) Pure Appl Chem 78:145-196

16. International vocabulary of metrology-basic and general concepts and associated terms JCGM 200:2012, www.bipm.org/vim

17. ISO 5725-5:1998/Cor 1:2005: Accuracy (trueness and precision) of measurement methods and results-part 5: alternative methods for the determination of the precision of a standard measurement method. International Organization for Standardization, Geneva 